\title{
Population characteristics and habitat suitability of Asian elephants (Elephas maximus Linnaeus, 1758) in the Khao Yai National Park, Thailand
}

$I_{\text {Forest Biology Depart- }}$ ment, Faculty of Forestry Kasetsart University, Chatuchak District,

Bangkok, Thailand 10900 Corresponding author, E-mail:fforrls@ku.ac.th

${ }^{2}$ Khao Yai National Park Pakchong District, $\mathrm{Na}$ korn Ratchasima Province, Thailand 30450

Mananya Pla-ard ${ }^{1}$, Ronglarp Sukmasuang ${ }^{1}{ }^{*}$, and Khanchit Srinopawan ${ }^{2}$

\section{ABSTRACT}

The aim of this study was to investigate the population and habitat of wild elephants in the Khao Yai National Park, to provide elephant population densities using the line transect method. Habitat suitability was also assessed based on the data obtained from the location of the species during monthly ranger patrol across the park area, with the rate of dung decay used for population calculation. The population structure and age class were studied by direct observation to estimate the population trend. On the basis of 116 systematic transect lines that were $2 \mathrm{~km}$ in length and separated by 500-m intervals, a total of 1,209 elephant dung piles were found in more than $213.20 \mathrm{~km}$. The analysis of the combined data showed that the dung density was 531.49 dung piles $/ \mathrm{km}^{2}$, with a decay rate of 0.0039 dung piles/day based on 56 dung piles checked every 7 days. The annual data showed that the population density was 0.15 individuals $/ \mathrm{km}^{2}$. The population structure comprising calf:juvenile:subadult:adult was 1: 1.09:1.14:2.10; the sex ratio of adult male to adult female elephants was 1:1.10; and the ratio of reproductive ability among adult females, juveniles, and calves was 1.00:0.99:0.90. The combined data also showed that the main environmental factor affecting the presence of the animals was salt lick sites. The pooled data analysis found that the habitat most suitable for the elephants covered an area of $220.59 \mathrm{~km}^{2}$. The habitat suitability, based on the dry season appearance data, covered an area of $258.64 \mathrm{~km}^{2}$, whereas during the wet season, it covered an area of $517.45 \mathrm{~km}^{2}$. As the most suitable habitat for elephants appears around the park boundary, habitat improvements for wild elephants should address the central areas of the national park. A greater emphasis should be placed on creating salt licks, being far from human activity sites. KEYWORDS

Line transect method; Wild elephant; Population characteristics

(c) BY-NC-ND $\odot 2019$ Mananya Pla-ard et al.

This is an open access article distributed under the Creative Commons Attribution-NonCommercial-NoDerivs license

\section{INTRODUCTION}

The increased need for natural resources to support the growing human population has caused loss, degradation, and conflict between humans and wildlife (FAO 2009). This has become an increasing problem throughout the world, affecting food security, society, the economy, the environment, and overall natural resources (Seoraj-Pillai \& Pillay 2017). In Asia, the conflict between humans and wildlife species has mainly been restricted to large carnivores (e.g., tigers [Panthera tigris], leopards [Panthera pardus], lions [Panthera leo], snow leopards [Panthera uncia], and wild elephants [Elephas maximus], across a range of countries (e.g., Barnes 1996; Treves \& Naughton-Treves 1999; Madhusudan 2003; Zhang \& Wang 2003; Van de Water \& Matteson 2018). In Thailand, the conflict between humans and elephants has existed for 100 years when more than 1,000 wild elephants came to forage in agricultural land within the Thung Rangsit area (Faculty of Forestry 2013). To date, human-elephant interaction has been reported around the borders of 42 of the 69 protected areas in Thailand that still contain elephants (Faculty of Forestry 2013).

The most important habitat for wild elephants is in the northeast of Thailand at the Khao Yai National Park (KYNP) (Storer 1981; Faculty of Forestry 2013). Similar to elsewhere, conflict has become a major problem to the endangerment of the elephant species (Choudhury et al. 2008). It has previously been reported that the wild elephant population in the KYNP is approximately between 100 and 200 elephants (Dobias 1985; Storer 1981). It has, therefore, been recommended that the KYNP is the best place to conduct elephant research and undertake technical training (Storer 1981). More recent scientific research has been conducted in the KYNP by Lynam et al. (2006), who used a camera trap method to report a relative abundance of wild elephants of $0.4 \pm 0.2$ individuals/100 trap nights $(n=121)$. Moreover, Kitamura et al. (2007) studied the role of fruit and seed dispersal by wild elephants in the KYNP by analyzing dung data. It was found that wild elephants play 
an important role in the wider distribution and germinating of plants compared with other herbivorous mammal species in the forest; demonstrating the important role of wild elephants in the ecosystem.

The KYNP and other surrounding protected areas were declared natural world heritage sites in 2005 (UNESCO 2019). This likely led to the dramatic increase in tourism, with more than 1,000,000 persons visiting per year since 2013 (National Parks Research and Innovation Development Center [NPRD] 2018) having a direct and/or indirect impact on the elephant's natural habitat. It was found that the wild elephants in the KYNP regularly roam outside the national park area to feed on agricultural crops. In addition, there have been continuous reports of conflicts between the local people and the wild elephants around the KYNP area. Indeed, there are frequent serious car accidents involving wild elephants, which occur on the roads near the national park. Consequently, the government has attempted to reduce the effect of recreational activities in the park in a number of ways, such as introducing automobile speed limits along the $42 \mathrm{~km}$ length of highway within the park, and in particular via public relations. However, there is a requirement for updated information related to the population characteristics of the elephant, to ensure the continued conservation of the species.

Line transect techniques have been improved to determine the elephant population and density in different forest habitats (Burnham et al. 1980). Line transect, using the dungs count method (see Barnes \& Jensen 1987; Dawson \& Dekker 1992), is currently the most common type of indirect census method for counting elephants in the wild (Hedges et al. 2012). Accordingly, the aim of this study was to determine the elephant density, population size, and habitat suitability in the KYNP using the systematic line transect dung count method, alongside recording elephant appearance during ranger patrolling. In particular, the objectives were to study the population characteristics, age structure, sex ratio, reproductive rate, and reproductive ability of the wild Asian elephants and to study the habitat suitability of the elephants within the KYNP. The results gained from this study are expected to provide up-todate information on the species status to enable the long-term conservation management of the area.

The size and location of a suitable habitat area for the population management was determined through a key habitat suitability assessment, using the data derived from park rangers about the presence of elephants in all habitats all year round.

\section{MATERIALS AND METHODS}

\subsection{Study site}

The KYNP is located in the eastern Dongrak mountain range on the Khorat Plateau in north eastern Thailand between $14^{\circ} 5^{\prime}-14^{\circ} 15^{\prime} \mathrm{N}$ and $101^{\circ} 5^{\prime}-101^{\circ} 50^{\prime} \mathrm{E}$ and covers an area of approximately $2,168 \mathrm{~km}^{2}$ (Figure 1 ). The elevation within the park ranges between 50 and 1,351 m, with the majority of the park's terrain between 400 and $800 \mathrm{~m}$. The KYNP is an important watershed in the region, regulating water resources to surrounding provinces. On the basis of 10 years of meteorology data around the head office in the park (2009-2018), the area receives $1,897 \mathrm{~mm}$ of annual rainfall with an average temperature of $21^{\circ} \mathrm{C}$. The north-eastern region of the park falls within a rain shadow area and has an annual rainfall of $1,300 \mathrm{~mm}$ (NPRD, 2018). The park's vegetation is dominated by evergreen forest cover, but it also has a wide range of other habitats, including dry mixed deciduous forests, grasslands, and agricultural areas. The diversity of the wildlife species is very high, with at least 71 mammal species, 447 bird species, 86 reptile species, and 18 amphibian species (Thai National Park 2019). The variety of wildlife found at the KYNP, includes four species of hornbills, Austen's brown hornbill (Anorrhinus austeni), Oriental pied hornbill (Anthracoceros albirostris), Great hornbill (Buceros bicornis), and Wreathed hornbill (Rhyticeros undulates); two species of gibbons, Lar gibbon (Hylobates lar) and Pileated gibbon (Hylobates pileatus); Clouded leopards (Neofelis nebulosa); Golden jackals (Canis aureus); Marbled cats (Pardofelis marmorata); Asian golden cats (Pardofelis temminckii); Malayan pangolins (Manis javanica); Dhole (Cuon alpinus); Sambar deer (Rusa unicolor); Barking deer (Muntiacus muntjak); Gaur (Bos gaurus); and Asian elephants (E. maximus) (Srikosamatara \& Hansel 1996; Trisurat et al. 1996).

The KYNP was declared as Thailand's first national park in 1962 and was declared as part of a natural world heritage site by UNESCO in 2005. Owing to the diverse flora and fauna, the world natural heritage site comprised of five almost contiguous protected areas: Khao Yai National Park, Thap Lan National Park, Pang Sida National Park, Ta Phraya National Park, and Dong Yai Wildlife Sanctuary, covering a total area of approximately $6,155 \mathrm{~km}^{2}$ (UNESCO 2019). The area harbors one of the largest and healthiest wild elephant populations under protection, with the estimated population between 100 and 150 individuals (Dobias 1985).

\subsection{Methodology}

\subsubsection{Dung count method}

Most estimates of elephant populations are based on 3 variables: (1) dung density, (2) dung decay rate, and (3) daily defecation rate (Barnes 2001). Dung density estimates can be standardized using distance sampling (Thomas et al. 2010). In regards to dung density, sampling was completed using randomly located transects as follows: first, a grid with a dimension of $1 \mathrm{~km} \times 1 \mathrm{~km}$ was overlaid on 1:50,000 topographic maps of the KYNP, with all grids numbered. A total of 58 grids (blocks) were selected using a systematic random sampling method. Within each selected grid, 2 transect lines of 2-km length were laid with 500-m intervals, aligned to ensure that they ran across altitudinal gradients or drainage patterns. Of 116 transects, a total of $231.20 \mathrm{~km}$ were used for only one of the surveys. On transects, whenever elephant dung was sighted, the 


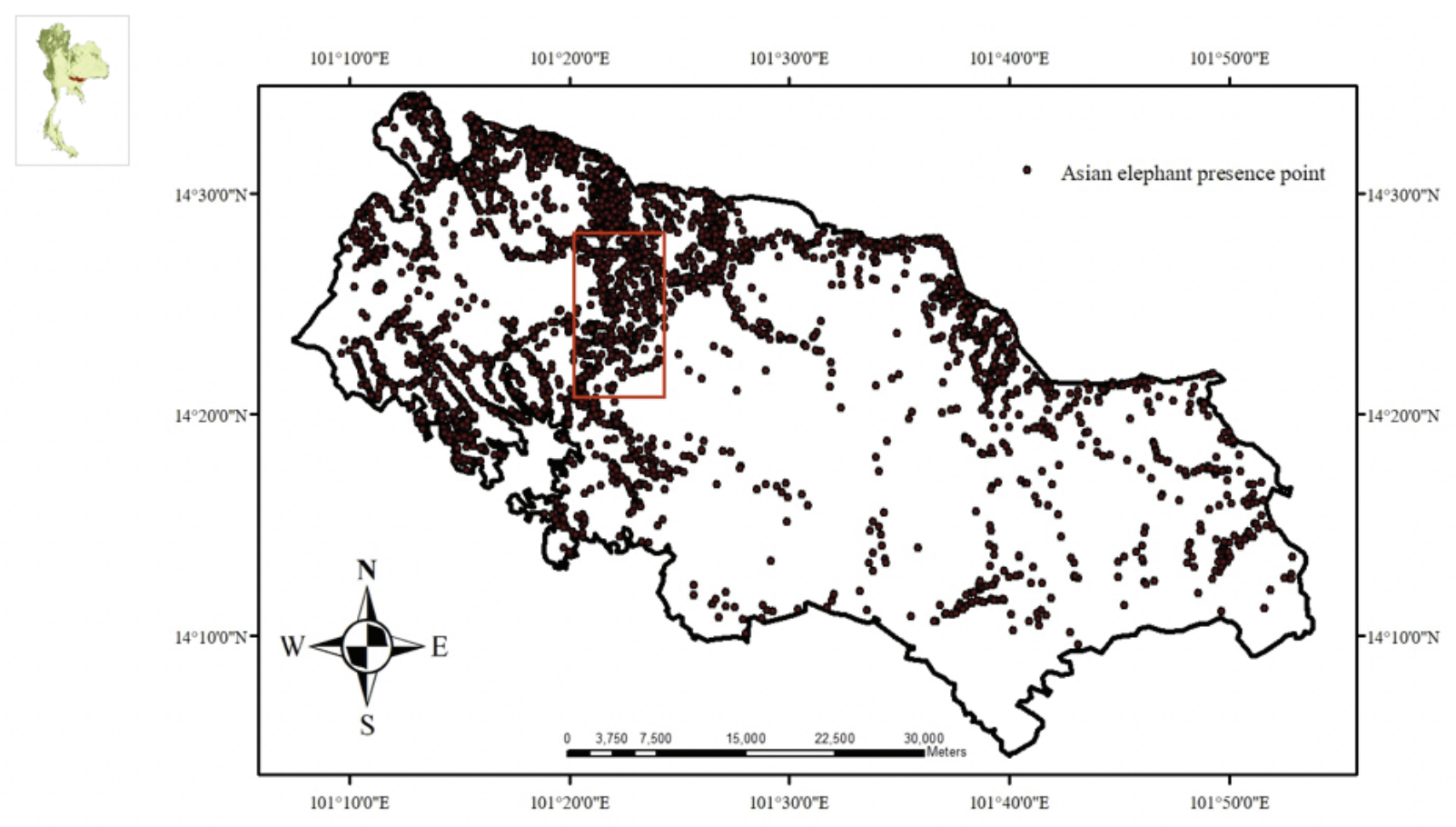

Figure 1. Boundary map of the Khao Yai National Park showing the study area (red rectangle) and the elephant distribution within the park observed by the smart patrolling system, which was undertaken regularly during November 2017 to October 2018.

Sources: (K. Srinopawan, 2019 personal communication)

perpendicular distance between the center of the dung and the center of the transect was measured.

The estimation of the elephant's dung density were analyzed following line transect analysis guidelines and were computed using the software Distance v6.2 (Thomas et al. 2010). In the first exploratory phase, there was a need to build up boxplots of perpendicular distances to identify outliers. These outliers were then removed from the data set via setting up of a proper truncation level. In a second step, the probability of next detection was estimated using seven models, combining probability density function (uniform, half normal, and hazard rate) with adjustments (cosines, simple, and Hermite polynomials). The model with the lowest Akaike's information criterion (AIC) was selected for each sampling unit. There was a need to create a data file containing the data on perpendicular distances, with a program used to read the file and calculate the perpendicular distances $f(0)$; an estimate of the reciprocal of the effective strip width (ESW). This was defined as the perpendicular distance for which the number of dung piles missed between the line and the ESW is equal to the number of dung piles that are detected beyond the ESW (Thomas et al. 2010; Alfred et al. 2010).

A general formula was used to calculate the density of dung piles $(D): D=n \cdot F(0) / 2 L$, where $n$ is the number of droppings, $L$ is the total length of transects in which they were recorded, and $F(0)$ is the probability density function of the detected distances from the line, evaluated at zero distances
(Burnham et al. 1980). The calculation was automatically completed using the program Distance V6.2 (Thomas et al. 2010). The population size $(\mathrm{N})$ of the park was estimated based on the size of the total park area and the population density per square kilometer (Ramakrishnan et al. 1991; Dawson \& Dekker 1992).

\subsubsection{Rate of dung decay}

The rate of dung decay depends on a combination of several factors, including the action of many species of dung beetles, exposure to different climatic factors, and the composition of the dung itself. Ideally, fresh dung piles of known dates of deposition from different habitats, representing different diets, should be monitored from the day of deposition until they disappear completely (Dawson \& Dekker 1992). The rate of decay measurement was carried out using 56 dung piles in the KYNP, with the dung piles located in forests, which had various conditions and were not far from a road. The forests included (1) closed canopy (forest canopy ranging between $80 \%$ and $100 \%$, which represents a dry evergreen forest), (2) semi-closed canopy (forest canopy ranging between $40 \%$ and $80 \%$, which normally represents a secondary forest), and (3) open canopy (forest canopy ranging between $0 \%$ and $40 \%$, which represents a grassland habitat). The decay condition was recorded for every 7 days, based on the categories identified by Barnes and Jensen (1987). The dung decay observations were carried out from January 2016 to January 2017. 
The analysis of the dung decay data was completed using the exponential and the survival methods. The exponential method assumes that dung decays exponentially, and, therefore, the equation of exponential decay is used to estimate the mean daily rate of decay (Barnes \& Jensen 1987). The exponential equation is

$N_{t}=N_{0} e^{-r t}$

where

$\mathrm{N}_{\mathrm{O}}$ = initial number of droppings;

$\mathrm{N}_{\mathrm{t}}$ = number left after $\mathrm{t}$ days;

$r$ = rate of decay

Taking natural logarithms (In), the equation becomes

$\ln \left(N_{t}\right)=\ln \left(N_{0}\right)-r t$

Alternatively,

$r=\left(\ln \left(N_{0}\right) \cdot-\ln \left(N_{t}\right)\right) / t$

The daily defecation rate is an important variable in the density estimation of the Asian elephant. On the basis of the formula of Dawson (1991) and Varman et al. (1995), in order to convert dung density into elephant density, this study used a defecation rate of 14.00, which was calculated from captive elephants at the Elephant Conservation Center, Lampang Province (Sukmasuang 2009).

\subsubsection{Population estimation}

The elephant's dung density was estimated using the line transect method (Burnham et al. 1980). On the basis of the method of Dekker et al. (1991) and Varman et al. (1995), the estimation of the elephant density was calculated using the following formula:

$E=(Y \times r) / D$

where

$E=$ density of elephants,

$\mathrm{Y}=$ density of dung,

$r=$ daily rate of decomposition,

$D=$ the number of dung piles deposited per elephant per day.

\subsubsection{Population structure}

Classification of the elephant population structure, sex, and age of the elephant from the direct sighting was performed by considering the size and shape, height, and external organs. Analyze from the shoulder height and divide into four classes, including calf, juvenile, subadult, and adult (Sukumar 1989; Arivazhagan \& Sukumar 2008; Varma et al. 2012).

\subsubsection{Habitat suitability}

In order to find the elephants' suitable habitat, the data obtained from smart patrolling between November 2017 and October 2018 specifically the environmental factors that affect habitat selection, were analyzed using MaxEnt software (Phillips 2008). The GPS locations of the animal and the direct and indirect recordings from rangers walking on transect lines during monthly park patrolling were used to find any relation with other environmental factors.

The environmental factors were divided into two groups: a biological environmental factors group, including plant society types, and another group containing six physical environmental factors, including altitude above mean sea level, slope and distance from water sources, salt licks, roads, and recreational areas.

The data were then converted into raster data for analysis. The two types of data were (1) continuous data, which included the altitude above mean sea level, slope, distances from water sources, saltlicks, roads, and recreational areas; and (2) category data, including plant society. A model of the distribution and probability of occurrence in the habitat relating to the environmental factors of the wild elephants was then produced by dividing the data into 2 sets with a 75:25 ratios; $75 \%$ of the data were tested with the MaxEnt program and $25 \%$ were used for data verification.

The equal training sensitivity and specificity used the logistic threshold criteria to divide the data into the presence and absence, and the percentage contribution of each environmental factor from testing the model showed the evaluation of the relationship between the animal presence locations and the main environmental factors (Phillips \& Dudik 2008).

\section{RESULTS AND DISCUSSION}

\subsection{Dung density}

On the basis of 116 transect lines, with each line of $1-2 \mathrm{~km}$ in length and a total length of $213.20 \mathrm{~km}, 1,209$ dung piles were found. The overall dung density was 531 dung piles $/ \mathrm{km}^{2}$ (95\% confidence interval [Cl]: 433.7-651.4) with a $10.3 \%$ CV. During the dry season, 36 transect lines with a total $73.3 \mathrm{~km}$ length were tested and 511 dung piles were found. The dung density was 841.9 dung piles $/ \mathrm{km}^{2}(95 \% \mathrm{Cl}$ : $608.0-1,165.7)$ with a $16.2 \% \mathrm{CV}$. In the wet season, 70 transects with a total length of $139.7 \mathrm{~km}$ were tested and 699 dung piles were found. The dung density was 468.6 dung piles $/ \mathrm{km}^{2}$ (95\% Cl: 359.5-610.7) with a $13.4 \% \mathrm{CV}$.

\subsection{Rate of decay}

In the present study, we found that based on 56 dung piles, the average number days of decay was $189 \pm 29.8$ days, with the mean dung decay rate estimated as 0.003927827 (SE = 0.000338435 ; Figure 2). The decay rate was slower than the 102.8 days previously reported by Collins (2018), who found a mean daily dung decay value of 0.0097 based on 14 dung piles 


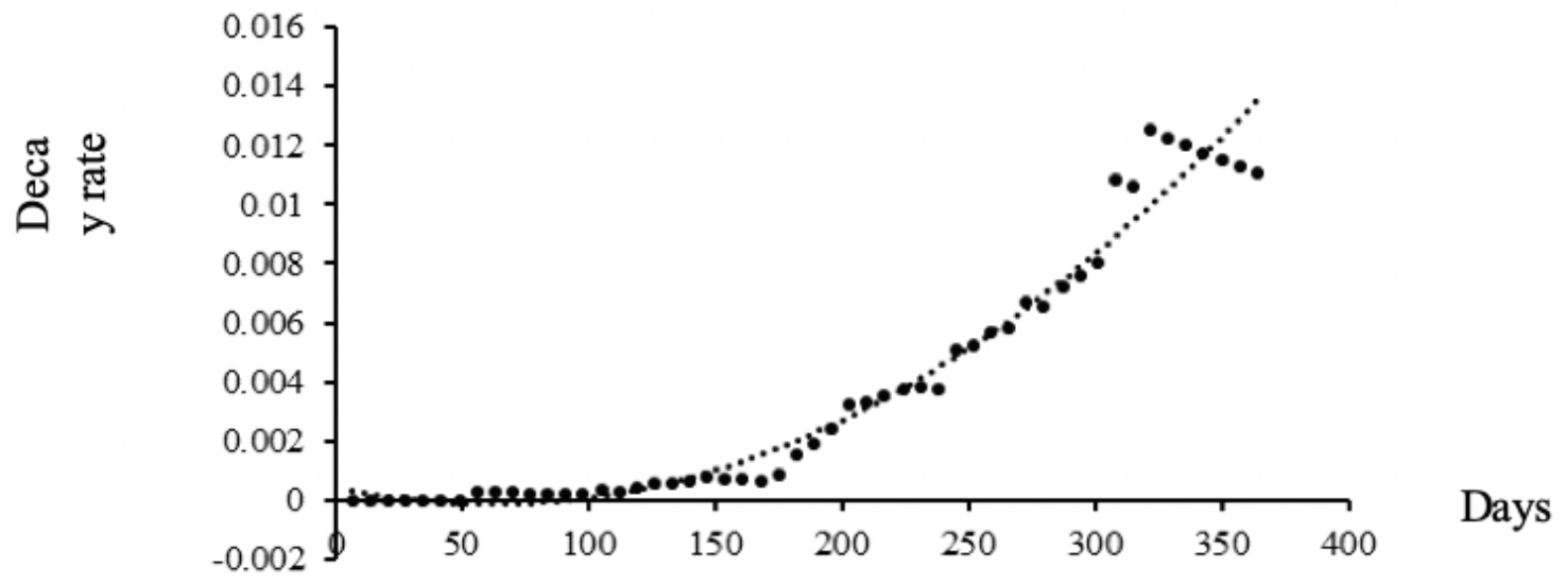

Figure 2. Relationship between days and decay rate of 56 fresh elephant dung piles in the KYNP

in the Leuser Ecosystem, North Sumatra. Similarly, Barnes and Barnes (1992) previously reported a slower daily dung decay rate $(0.022-0.026)$ in Africa, which was in agreement with White's (1995) and Nchanji and Plumptre's (2001) observations of 0.018 and $0.013-0.007$, respectively. However, our results are in line with Vanleeuwe and Probert's (2014) findings, who investigated dung decay based on 57 dung piles between March and September 2005 at the Conkouati-Douli National Park in the Republic of Congo. In their study, the majority of the dung piles $(75.4 \%, n=43)$ were found in forest habitats, with $12 \%$ ( $n$ $=7)$ in scrub, $10 \%(n=6)$ in savanna grasslands, and $1.8 \%(n=$ 1 ) in farmland. The mean survival time of the dung piles were 158.3 days ( $S D \pm 12.6$ ) with a mean decay rate of 0.00637 per day $(S D \pm 0.0007)$.

\subsection{Elephant Population densities}

In the past, the total population in the KYNP was estimated by interviewing the park rangers with secondary data (Faculty of Forestry 2013). The study area covered all types of habitats used by the wild elephants in the KYNP and was based on habitat suitability from elephant maps. Thus, the estimated total population was 300 individuals with a $95 \% \mathrm{Cl}$ of $240-360$ individuals. The estimation followed the method of Dawson and
Dekker (1992), who derived their estimation by extrapolating from the area (Table 1).

The defecation rate studied at the Elephant Conservation Center in Lampang Province showed an average defecation rate of 14.00 dungs/day (Sukmasuang 2009). Thus, the population density was 0.15 individuals $/ \mathrm{km}^{2}$, with a narrow $\mathrm{Cl}$ of $0.12-0.18$ individuals $/ \mathrm{km}^{2}$. The density during the dry season was 0.24 individuals $/ \mathrm{km}^{2}$ with a narrow $\mathrm{Cl}$ of 0.17 to 0.32 individuals $/ \mathrm{km}^{2}$, whereas during the wet season, the density was 0.13 individuals $/ \mathrm{km}^{2}$ with a narrow $\mathrm{Cl}$ of $0.10-0.17$ individuals/ $\mathrm{km}^{2}$ (Table 1).

The systematic line transect, which was used to study the elephant population in its natural habitat, presented only three protected areas in Thailand. The population densities gained from this study were lower than the densities in Huai Kha Khaeng and Khao Ang Rua Nai Wildlife Sanctuaries, which reported 0.30 individuals $/ \mathrm{km}^{2}$ (Sukmasuang 2009) and 0.62 individuals $/ \mathrm{km}^{2}$ (Wanghongsa \& Boonkird 2004), respectively. However, the population density was higher than at the Phu Woa Wildlife Sanctuary, which was only 0.10 individuals $/ \mathrm{km}^{2}$ (Chokchareon \& Sukmasuang 2012). The total estimated elephant population in the KYNP was approximately 300 individuals when accounting for the total park area.

Table 1. Dung density and population density of wild elephants estimated using the line transect and the dung count method at two different study sites the Khao Yai National Park, Nakhon Ratchasima Province, Thailand

\begin{tabular}{|c|c|c|c|c|c|c|}
\hline Season & $\begin{array}{c}\text { No. of transect } \\
\text { lines }\end{array}$ & $\begin{array}{c}\text { Transect } \\
\text { length } \\
(\mathrm{km})\end{array}$ & $\begin{array}{c}\text { No. of } \\
\text { dung piles }\end{array}$ & $\begin{array}{l}\text { Dung density } \\
\qquad(95 \% \mathrm{Cl})\end{array}$ & $\% \mathrm{CV}$ & $\begin{array}{l}\text { Population density } \\
\qquad(95 \% \mathrm{Cl})\end{array}$ \\
\hline Dry & 36 & 73.29 & 531 & $\begin{array}{c}841.85 \\
(608.00-1,165.70)\end{array}$ & 16.22 & $\begin{array}{c}0.24 \\
(0.17-0.32)\end{array}$ \\
\hline Wet & 78 & 139.71 & 699 & $\begin{array}{c}468.56 \\
(359.50-610.71)\end{array}$ & 13.37 & $\begin{array}{c}0.13 \\
(0.10-0.17)\end{array}$ \\
\hline Overall & 115 & 213.20 & 1,209 & $\begin{array}{c}531.49 \\
(433.69-651.36)\end{array}$ & 10.30 & $\begin{array}{c}0.15 \\
(0.12-0.18)\end{array}$ \\
\hline
\end{tabular}


A study by Kumara et al (2012) used 33 transects with a total length of $93 \mathrm{~km}$ at Biligiri Rangaswamy Temple Tiger Reserve in India. These transects amounted to a total of 795.5 $\mathrm{km}$ of walks and resulted in an elephant density of 1.7 animals, and a total of 713 elephants for $610 \mathrm{~km}^{2}$. Therefore, our data showed a lower elephant population density in the KYNP compared with the Tiger Reserve of India.

\subsection{Population structure and age ratio}

On the basis of 71 direct observations during January 2016 to March 2017, 112 individuals were observed and identified. There were 21 calves, 23 juveniles, 24 subadult, and 44 adult elephants. The population structure comprising calf:juvenile:subadult:adult was 1:1.09:1.14:2.10. The sex ratio of adult male:adult female was 1:1.10, and the ratio of reproductive ability between adult females, juveniles, and calves was 1.00:0.99:0.90.

Kumara et al. (2012) reported a sex ratio of adult male:adult female of 1:4.1 and a ratio of adult female:immature elephant ratio of 1:0.35. These findings reflected the past severe poaching of male elephants, with poaching likely lowering the calf-to-adult female ratio. This would affect birth rates and disturb the demographic structure, inhibiting the long-term survival of elephants (Sukumar et al. 1998; Foley et al. 2001).

In this study, the sex ratio between adult male and adult female was classified as normal when compared with the normal ratio of 1:1.87 and 1:1.85 reported in the Rajaji National Park in India (Williams et al. 2007) and Ruhuna National Park in Sri Lanka (Katugaha et al. 1999), respectively. De and Spillet (1966) suggested that a greater or less than 1:1 sex ratio may usually be found in an area free from selective shooting or predation. Poaching of adult male Asian elephant (E. maximus) has significantly altered their sex ratio in the Western Ghats (Arivazhagan 2005; Sukumar 2006). Therefore, because of the normal sex ratio found in this study, it may be speculated that there has not been any significant elephant poaching within the KYNP for a considerable time.

\subsection{Habitat suitability}

The smart patrol system showed that there were 1,129 locations of elephant data found annually in the KYNP, with more than 531 locations during the dry season and 598 locations during the wet season. Habitat selection was analyzed using the data obtained from smart patrolling within the KYNP, together with data of the biological and physiological environmental factors, namely, plant community types and the six physical environmental factors, including (1) slope, (2) elevation, (3) distances from permanent water sources, (4) salt lick sites, (5) roads, and (6) recreational areas, using the maximum entropy in the MaxEnt program. It was found that the probability of the occurrence of elephants for the whole year, during the dry season and the wet season, was related to the different environmental factors:

The analysis of the annual data showed that the AUC indicated an accuracy of 0.88 , meaning that the model was highly reliable with $88 \%$ accuracy (Fawcett 2006). We found that the environmental factor that had the greatest influence on the percentage occurrence of the elephants over the year (November 2017 to October 2018) was salt licks (59.70\%), followed by the altitude above mean sea level (10.20\%), distance from permanent water sources $(9.20 \%)$, and distance from a road $(7.30 \%)$. The other environmental factors had less relation to the presence of elephants over the year (Table 2).

The results of the smart patrolling data showed the probability distribution of the occurrence of the wild elephants over the year. We found that the total area could be divided into areas where there was a high probability of elephant presence, approximately $220.59 \mathrm{~km}^{2}$.

The wet season in this study was from May 2018 to October 2018. The model analysis found that the AUC was 0.89 , which indicated an $89.00 \%$ reliability of the elephant habitat model (Fawcett 2006). The environmental factor that had the greatest influence on the percentage probability of the presence of the wild elephants in the wet season was the distance from the salt licks $(47.20 \%)$, followed by the distance from a road $19.60 \%)$, forest type (12.30\%), distance from the

Table 2. Percentage contribution of the environmental factors that affect wild elephant appearances in the Khao Yai National Park, which were analyzed by season and data combined during November 2017 to October 2018.

\begin{tabular}{c|c|c|c}
\hline \multirow{2}{*}{ No. } & Environmental factors & \multicolumn{2}{|c}{ Percent contribution } \\
\cline { 2 - 4 } & Distance from the salt licks & Dry & All year \\
\hline 1 & Altitude above mean sea level & 55.60 & 47.20 \\
\hline 2 & Distance from permanent water sources & 13.30 & 10.20 \\
\hline 3 & Distance from road & 12.70 & 3.10 \\
\hline 4 & Slope class & 9.70 & 19.60 \\
\hline 6 & Distance from recreation zone & 4.60 & 3.20 \\
\hline 7 & Total & 3.00 & 10 \\
\hline
\end{tabular}


recreation zone (7.80\%), and altitude above mean sea level (6.80\%). The other environmental factors were less related to the elephant presence in the wet season.

The smart patrolling in the KYNP area showed that the probability distribution of the wild elephant presence in the wet season was approximately $517.46 \mathrm{~km}^{2}$ and demonstrated a high possibility of elephant presence.

In the dry season, between November 2017 and April 2018, data were also obtained from smart patrolling. The model analysis showed that the AUC values were very close to $1(0.888)$, which indicated that the elephant habitat model had $88.80 \%$ reliability (Fawcett 2006 ).

By considering the environmental factors that are related to the percentage probability of the presence of wild elephants in the dry season, it was found that the distance from the salt licks was the environmental factor that had the most influence on the elephants $(55.60 \%)$, followed by altitude above mean sea level (13.30\%), distance from permanent water sources $(12.70 \%)$, distance from a road $(9.70 \%)$, slope class $(4.60 \%)$, forest type $(3.00 \%)$, and the distance from the recreation zone (1.00\%). The distribution of the wild elephant probability of the presence in the dry season showed the area that had a high possibility of elephant presence, which covered approximately $258.64 \mathrm{~km}^{2}$.

The wild elephant annual habitat use in the KYNP during both the dry and wet seasons showed that the distance from salt licks and the distance from artificial water sources gave the highest probability of wild elephant occurrence. These findings are consistent with Chaiyarat et al.'s (2015) observations, who studied the wild elephant habitat use in Salakpra Wildlife Sanctuary, Kanchanaburi Province, between May 2010 and March 2011. The analysis of the Relative Abundance Index (RAI) of wild elephants from photographs showed that artificial water sources had the highest RAl, followed by salt licks. Our study findings are also in agreement with Menkham et al. (2019), who confirmed that salt licks and artificial water sources were the environmental factors that had the most influence on the probability of occurrence of the elephant.

Pooled data showed that the factors that affected the elephants' presence were the distance from salt lick sites (59.7\%), whereas during the dry and the wet seasons, the distance from salt licks affected the animals' presence at $55.60 \%$ and $47.20 \%$, respectively. The other factors that affected the elephants' presence were (in order) altitude, distance from permanent water sources, distance from a road, slope class (percent change in topographical elevation), forest types, and distance from the recreation zone (Table 2). The combined data analysis showed that the most suitable area for elephants covered $220.59 \mathrm{~km}^{2}$, whereas during the dry and the wet seasons, the most suitable area covered an area of 258.64 and 517.46 $\mathrm{km}^{2}$, respectively (Figure 3 ).

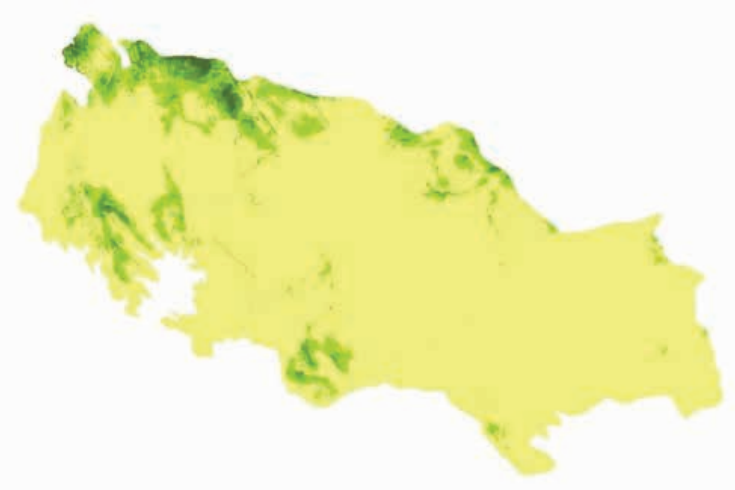

(a)

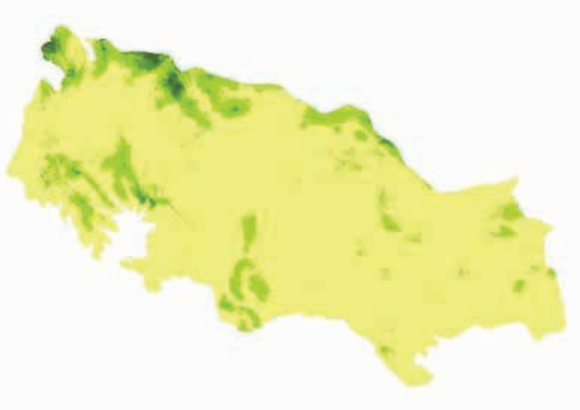

(b)

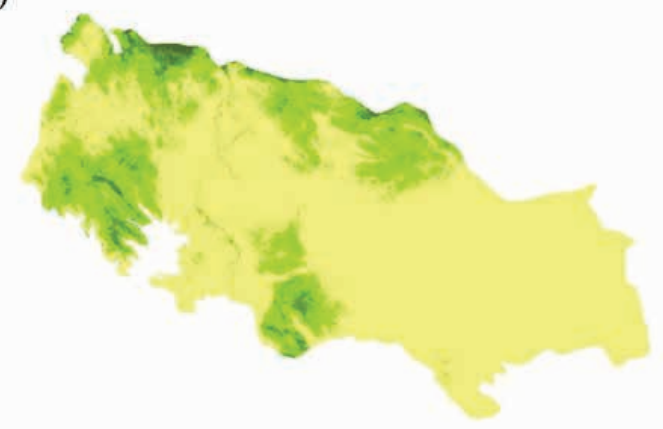

(c)

Figure 3. Habitat suitability maps for wild elephants in the Khao Yai National Park, analyzed using annual data and separated into dry and wet seasons: (a) all year, (b) dry season, and (c) wet season. Dark green area represents the suitable habitat for the elephants, followed by the light green and yellow areas respectively. 


\section{CONCLUSIONS AND RECOMMENDATIONS}

We found that the density of wild elephants in the KYNP was 0.15 individuals $/ \mathrm{km}^{2}$, with a total population of approximately 300 individuals. The proportion of the adult sex ratio was very similar and showed very little variation in gender, with a normal population structure ratio identified. On the basis of our study, the population growth rate was calculated as 118 adult wild elephants, with 62 adult female elephants based on the ratio adult male to adult female elephants. Therefore, considering the ratio of adult female elephants to calves found in the population was 1: 0.90, there were also new born wild elephants in the population of 56 individuals. However, as female wild elephants have a gestation period of 22 months (Lueders et al. 2012) and raising new born requires approximately $3-4$ years, the length of pregnancy and breast-feeding of female elephants requires 5-6 years (Fowler \& Mikota 2006).

Therefore, the number of new born elephants relates to the number of wild elephants in the past 5-6 years. Thus, each year, approximately 9-11 wild elephants emerge, excluding deaths in the population. Considering the results of Dobias (1985), who reported an average population of 150 wild elephants in the KYNP, our findings suggest that the population has increased by approximately 150 individuals in the past 34 years.
The habitat suitability analysis showed that salt lick sites, recreational areas, and permanent water sources were the important factors affecting the appearance of elephants in the area. Recommendations for further elephant management involve creating salt lick sites in areas far from the roads and the recreation areas of the park. In relation to the suitability of the elephants' habitat, it was found that the park boundary was most suitable. Therefore, habitat improvements for wild elephants should improve the areas within the national park and especially address the central area, with an emphasis on creating salt licks, the most important habitat factor for wild elephants.

\section{ACKNOWLEDGMENTS}

This study was supported by the Khao Yai National Park and funded by the National Research Council of Thailand (NRCT). We would like to thank the Coordinating Center for Thai Government Science and Technology Scholarship Students (CSTS) and the National Science and Technology Development Agency (NSTDA), Thailand, for supporting a Ph.D. scholarship. We would like to thank the dean of the Faculty of Forestry who supported this study and the Director of the National Park Office, DNP, and also Mr. Panakorn Klaomklang and staff at the park for the accommodation and support. We would like to thank Mr. Paanwaris Paansri for preparing the distribution map.

\section{References}

Alfred, R., Ahmad, A. H., Payne, J., William, C., Ambu, L., et al. (2010) Density and Estimation of the Bornean Elephants (Elephas maximus borneensis) in Sabah. OnLine Journal of Biological Sciences, 10 (2), 92-102.

Arivazhagan, C. (2005) Population dynamics of Asian elephant (Elephas maximus) in Southern India. Ph.D Thesis, Bharathidasan University, Trichy, India.

Arivazhagan, C. \& Sukumar, R. (2008) Constructing age structure of Asian elephant populations: a comparison of two field methods of age estimation. Gajah, 29, 11-16.

Barnes, J.I. (1996) Changes in the economic use value of elephant in Botswana: the effect of international trade prohibition. Ecological Economics, 18 (3), 215-230.

Barnes, R.F.W. (2001) How reliable are dung counts for estimating elephant numbers? African Journal of Ecology, 39, 1-9.

Barnes, R.F.W. \& Barnes, K.L. (1992) Estimating decay rates of elephant dung piles in forest. African Journal of Ecology, 30, 316-321.

Barnes, R.F.W. \& Jensen, K.L. (1987) How to count elephants in forests. IUCN African Elephants and Rhino Specialist Group: Technical Bulletin, 1, 12-87.

Burnham, K.P, Anderson, D. R., Laake J.L., et al. (1980) Estimation of density from line transect sampling of biological populations. Wildlife Monograph, 72, 1-202.
Chaiyarat, R., Youngpoy. N., Prempree, P., et al. (2015) Wild Asian elephant Elephas maximus population in Salakpra Wildlife Sanctuary, Thailand. Endangered Species Research, 29, 95-102.

Chokcharoen, R. \& Sukmasuang, R. (2012) Ecology of Asian elephant (Elephas maximus) in Phu Wua Wildlife Sanctuary, Bueng Kan Province. Journal of Wildlife in Thailand, 19, 13 -22 (in Thai).

Choudhury, A., Choudhury, L., Desai, A.A., Duckworth, J.W., Easa, P.S., Johnsingh, A.J.T., Fernando, P., Hedges, S., Gunawardena, M., Kurt, F., Karanth, U., Lister, A., Menon, V., Riddle, H., Rübel, A., Wikramanayake, E., et al. (2008) Elephas maximus. The IUCN Red List of Threatened Species 2008: e.T7140A12828813. Retrieved from http://dx.doi.org/10.2305/IUCN.UK.2008.RLTS T7140A12828813.en.

Collins, N.J. (2018) Sumatran elephant Elephas maximus sumatranus density and habitat use in relation to forest characteristics in the Leuser Ecosystem, North Sumatra. M.Sc. Thesis, Bournemouth University, UK.

Dawson, S. (1990) A model to estimate the density of Asian elephants (Elephas maximus) in forest habitats. M.Sc. thesis, University of Oxford, UK.

Dawson, S. \& Dekker, A.J.F.M., (1992) Counting Asian elephants in forests. FAO, Bangkok.

De, R.C. \& Spillet, J.J. (1966) A study of the Chital or spotted deer in Corbett National Park, Uttar Pradesh. Journal of the Bombay Natural History Society, 63, 576-598. 
Dekker, A.J.F.M., Dawson, S. \& Desai, A.A. (1991) An indirect method for counting Asian elephants in forests. In: U. Ramakrishnan, Santosh, J.A. \& Sukumar, R. (Eds.) Censusing Elephant in Forests, Proceedings of an International Workshop (2-10 January 1992, Bangalore, India), Asian Elephant Conservation Center, Bangalore, India, 54-64.

Dobias, R. (1985) Final report: WWF/IUCN Project 3001: elephant conservation and protected area management. WWF/IUCN, Royal Forest Department, Bangkok, Thailand.

Hedges, S. (2012) Estimating Elephant Population Density and Abundance from Dung Pile Density: Theoretical Concepts. In: S. Hedges (Ed.) Monitoring Elephant Populations and Assessing: Threats a manual for researchers, managers and conservationists ( $p p$. 61-111). Universities Press (India) Private Limited.

Faculty of Forestry (2013) Elephant Conservation and management plan. Faculty of Forestry, Kasetsart University Press. Bangkok. (in Thai)

FAO (2009) Human-wildlife conflict in Africa conflict in Africa causes, consequences Causes, consequences and management strategies and management strategies. Retrieved from http: //www. fao.org/3/i1048e/i1048e00.pdf.

Fawcett, T. (2006) An introduction to ROC analysis. Pattern Recognition Letters, 27, 861-874.

Foley, C.A.H., Papageorge, S., Wasser, S. K., et al. (2001) Non-invasive measures and reproductive measures of social and ecological pressures in free ranging African elephants. Conservation Biology, 14, 1134-1142.

Fowler, M.E. \& Mikota, S.K. (2006) Biology, medicine and surgery of elephants. Ames, IA: Wiley-Blackwell.

Katugaha, H.I.E., deSilva, M., Santiapillai, C., et al. (1999) A long term study on the dynamics of the elephant (Elephas maximus) in Ruhuna National Park, Sri Lanka. Biological Conservation, 89, 51-59.

Kitamura, S., Yumoto, T., Poonswad, P., Wohandee, P., et al. (2007) Frugivory and seed dispersal by Asian elephants, Elephas maximus, in a moist evergreen forest of Thailand. Journal of Tropical Ecology, 23, 373-376.

Kumara, H.N., Rathnakumar, S., Kumar, M.A., Singh, M., et al. (2012) Estimating Asian elephant, Elephas maximus, density through distance sampling in the tropical forests of Biligiri Rangaswamy Temple Tiger Reserve, India. Tropical Conservation Science, 5 (2), 163-172.

Lueders, I., Niemuller, C., Rich, P., Gray, C., Hermes, R., Goeritz, F., et al. (2012) Gestating for 22 months: luteal development and pregnancy maintenance in elephants. Proceedings of the Royal Society B: Biological Sciences, 279, 3687-3696.

Lynam, A.J., Round, P.D., Brockelman, W.Y., et al. (2006) Status of birds and large mammals in Thailand's Dong Phayayen - Khao Yai Forest Complex. Wildlife Conservation Society and Biodiversity Research and Training (BRT) Programme, Bangkok.

Madhusudan, M.D. (2003) Living amidst large wildlife: livestock and crop depredation by large mammals in the interior villages of Bhadra Tiger Reserve, South India. Journal of Environmental Management, 31 (4), 466-475.
Menkham, K., Sukmasuang, R., Pla-Ard, M., Charaspet, K., Panganta, T., Trisurat, Y., Bhumpakphan, N., et al. (2019) Population and habitat use of Asian elephants (Elephas maximus) and five ungulate species in Khao Ang Rue Nai Wildlife Sanctuary, Chachoengsao Province, Thailand. Biodiversitas, 20, 2213-2221.

National Parks Research and Innovation Development Center (NPRD) (2017) Attitudes and opinions of Thai tourists towards the conservation of crocodiles in Khao Yai National Park. National Parks Wildlife and Plant Conservation Department, Nakorn Ratchasima Province. (in Thai).

Nchanji, A.C. \& Plumptre, A.J. (2001) Seasonality in elephant dung decay and implications for censusing and population monitoring in south-western Cameroon. African Journal of Ecology, 39, 24-32

Phillips, S.J. (2008) A Brief Tutorial on Maxent. Retrieved from http:// www.cs.princeton.edu/ schapire/maxent/tutorial.doc.

Phillips, S.J. \& Dudík, M. (2008) Modeling of species distributions with Maxent: new extensions and a comprehensive evaluation. Ecography, 31(2), 161-175.

Ramakrishnan, U., Santosh, J.A., Sukumar, R., et al. (1991) Censusing elephants in forests. Asian Elephant Conservation Centre of IUCN/ SSG Asian Elephant Specialist Group, Bangalore, India.

Seoraj-Pillai, N. \& Pillay, N. (2017) A meta-analysis of human-wildlife conflict: South African and global perspectives. Sustainability, 9 (34), 1-21. Retrieved from DOI: 10.3390/su9010034

Srikosamatara, S. \& Hansel, T. (1996) Mammals of Khao Yai National Park. Green World Foundation, Bangkok.

Storer, P.J. (1981) Elephant Population in Thailand. Natural History Bulletin of Siam Society, 29, 1-30.

Sukmasuang, R. (2009) Population density of Asian elephants in Huai Kha Khaeng Wildlife Sanctuary. Thai Journal of Forestry, 28(1), $40-50$.

Sukumar, R. (1989) The Asian elephant: ecology and management. Cambridge University, New York.

Sukumar, R. (2006) A brief review of the status, distribution and biology of wild Asian elephant (Elephas maximus). International Zoo Yearbook, 40, 1-8.

Sukumar, R., Ramakrishnan, U., Santosh, J.A., et al. (1998) Impact of poaching on Asian elephant population in Periyar, southern India: a model of demography and tusk harvest. Animal Conservation, 1, $281-291$.

Thai National Park (2019) Wildlife in Khao Yai. Retrieved from https:// www.thainationalparks.com/khao-yai-national-park/wildlife.

Thomas, L., Buckland, S.T., Rexstad, E.A., Laake, J.L., Strindberg, S., Hedley, S.L., Bishop, J.R.B., Marques, T.A., Burnham, K.P., et al. (2010) Distance software: design and analysis of distance sampling surveys for estimating population size. Journal of Applied Ecology, 47, 5-14. Retrieved from DOI: 10.1111/j.13652664.2009.01737.x

Treves, A. \& Naughton-Treves, L. 1999. Risk and opportunity for humans coexisting with large carnivores. Journal of Human Ecology, 36, 275-282.

Trisurat, Y., Eiumnoh, A., Tharnchai, P., Phongpanit, K., et al. (1996) A geographical study of wildlife abundances in Khao Yai National Park, Thailand. Report submitted to 
Thailand Research Fund. School of Environment, Resources and Development, Asian Institute of Technology, Bangkok

UNESCO (2019) Dong Phayayen-Khao Yai Forest Complex. Retrieved from https://whc.unesco.org/en/list/590/.

Van de Water, A. \& Matteson, K. (2018) Human-elephant conflict in western Thailand: Socio-economic drivers and potential mitigation strategies. PLoS ONE, 13(6), e0194736. Retrieved from https://doi.org/10.1371/journal.pone.0194736.

Vanleeuwe, H. \& Probert., J. (2014) Decay rate of elephant dung in Conkouati-Douli National Park, Republic of Congo. Pachyderm, 55(55), 89-91.

Varman, K.S. \& Sukumar, R. (1995) The line transect method for estimating densities of large mammals in a tropical deciduous forest: An evaluation of models and field experiments. Journal of Biosciences, 20(2), 273-287.
Varma, S., Baskaran, N. \& Sukumar, R. (2012) Field key for elephant population estimation and age and sex classification. Asian Nature Conservation Foundation, Innovation Centre, Indian Institute of Science, Bangalore, India.

Wanghongsa, S. \& Boonkird, K. (2004) Estimating elephant populations in dry evergreen forest of Thailand. Retrieved from http://www. theeasternforest.org/pages/2547/Estimating.pdf.

Williams, C., Johnsingh, A. J. T., Krausman, P. R., et al. (2007) Population estimation and demography of the Rajaji National Park elephants, North-West India. Journal of Bombay Natural History Society, 104, 145-152.

White, L.J.T. (1995) Factors affecting the duration of elephant dung piles in rain forest in the Lope Reserve, Gabon. African Journal of Ecology, 33, 142-15.

Zhang, Li \& Wang, N. (2003) An initial study on habitat conservation of Asian elephant (Elephas maximus), with a focus on human elephant conflict in Simao, China. Biological Conservation, 112(3), 453-459. 